

\section{DISCLAIMER}

Portions of this document may be illegible in electronic image products. Images are produced from the best available original document. 


\section{$7 \cup 54: \pm 4 / F+$}

\section{DISCLAIMER}

This report was prepared as an account of work sponsored by an agency of the United States Government. Neither the United States Government nor any agency thereof, nor any of their employees, makes any warranty, express or implied, or assumes any legal liability or responsibility for the accuracy, completeness, or usefulness of any information, apparatus, product, or process disclosed, or represents that its use would not infringe privately owned rights. Reference herein to any specific commercial product, process, or service by trade name, trademark, manufacturer, or otherwise does not necessarily constitute or imply its endorsement, recommendation, or favoring by the United States Government or any agency thereof. The views and opinions of authors expressed herein do not necessarily state or reflect those of the United States Government or any agency thereof.

PERFORMANCE REPORT FOR A SMALL PACKAGE COUNTER THAT USES ACTIVE NEUTRON INTERROGATION ,

by

R. A. Harlan, B. E. Wishard, R. D. Santopietro and B. P. Anderson

Technology Development

Technical Investigations

TD -93003

JuTy 7,1993

Approved:

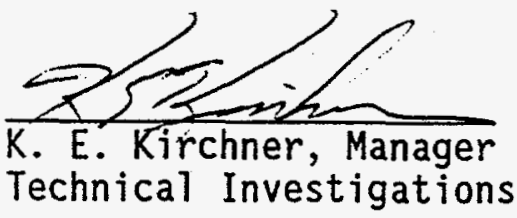

Distribution:

B. P. Anderson

R. A. Harlan

K. E. Kirchner

J. L. Peterson

N. R. Roberts

R. W. Tyler

B. E. Wishard

R. D. Santopietro

IRF / Library
DISTRIBUTION OF THIS DOCUMENT IS UNLIMITID

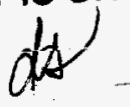

KWIC:

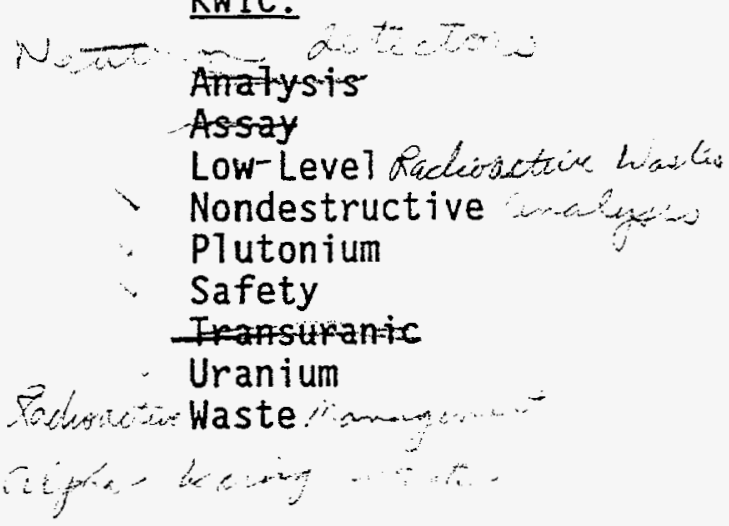

REVIENED FOR CLASSIFICATION

By D. G. Hinath (U)

Date $2-8-93$ 


\title{
PERFORMANCE REPORT FOR A SMALL PACKAGE COUNTER THAT USES ACTIVE NEUTRON INTERROGATION
}

\author{
R. A. Harlan, B. E. Wishard, R. D. Santopietro and B. P. Anderson \\ Technology Development, Technical Investigations \\ EG\&G Rocky Flats Plant \\ P. 0. Box 464 , Golden, CO $80402-0464$
}

\section{ABSTRACT}

An active neutron interrogation system utilizing the differential dieaway technique' (DDT), was built to assay fissile material in small waste packages for a variety of matrices. Within minutes the system can make a "go/no-go" decision for sorting low-level waste (LLW) from transuranic waste (TRUW). It can also provide gram-level accountability of weapons-grade (WG) Pu in TRUW providing lumps of self-shielding fissile material are absent.

\section{INTRODUCTION}

As the requirements for shipment to and storage of waste at the Waste Isolation Pilot Plant (WIPP) and the Nevada Test Site (NTS) continues to unfold, there is a growing need to develop and implement assay systems that can distinguish LLW from TRUW. This project originated with a U. S. Department of Energy request to determine what fraction of the waste being generated and handled as transuranic waste (TRUW) was in fact low level waste (LLW) at the Rocky Flats Plant during past normal production operations. DOE wanted a field demonstration of a detector system capable of determining what fraction of solid LLW was being misidentified as TRUW during past process operations. A Smal1 Package Counter (SPC) was designed for a rapid decision on the LLW vs TRU question and was not optimized as an assay device. DOE Order 5820.2A requires identification of $L L W$ and TRUW so that segregation can be made at the earliest technically feasible time.

The planned experimental program was not done because a Plant shutdown beginning in 1990 stopped production. However, a new need to minimize waste led to a new mission for the Small Package Counter that was received on site after the shutdown.

A Supercompactor was being installed for volume reduction of TRU and LLW waste. It was anticipated by the Safeguards Measurements group that waste to be compacted would have some items that would not meet criteria for compaction. Those items were called "non-conforming" items. If nonconforming items were removed from the pre-compaction sorting table and bagged out, an accountability value would need to be measured so that material control and accountancy could be maintained for the remaining to-be-compacted waste batch. Measurements of fissile material in non-conforming items are the latest mission for the Small Package Counter. 
The ability to sort will also allow assignment as $L L$ or TRU wastes and allow operators to put waste into the proper type of drum for later disposition. A corollary benefit will be improved safety in loading TRU waste drums because the gram value will be available for a package that has been assayed. This will obviate the need for taking the packages to another type of estimating device called a "Gram Estimator". The counter described herein is expected to be more accurate than gram estimators for most waste forms.

The ability to differentiate $L L W$ requires an assay system with a "minimum quantifiable limit" below $100 \mathrm{nCi} / \mathrm{gram}$. To obtain this sensitivity in a wide variety of matrices the SPC utilizes the "differential dieaway technique" (DDT) ${ }^{1}$. That is an active interrogation method of neutron counting, which takes advantage of the timing differences between thermalizing a pulse of $14.7 \mathrm{MeV}$ neutrons and the inducement of a 2 nd generation of neutrons from fission events induced by the thermal neutrons after the pulse. In a given counting time, DDT typically has a lower limit of detection $\left(L_{0}\right)$ an order of magnitude better than other neutron/gamma techniques ${ }^{2}$. In the SPC the $L_{0}$ at $4 \sigma$ above mean background was approximately $2.5-\mathrm{mg}$ weapon grade $\mathrm{Pu}$ (WG Pu).

The active neutron interrogation works briefly as follows. Accurate clocks turn on scalers when the 2nd generation of fission neutrons are near their peak intensity, but neutrons from the original pulse have left the sample chamber. The scalers turn on about 700 microseconds after the generator pulse and turn off at typically 4700 microseconds. Uncorrelated neutrons are counted in a later gate from perhaps 10 milliseconds to 20 milliseconds. These uncorrelated background neutron count rates are subtracted from rates in the earlier gate. The difference is related through calibration experiments to fissile material content. Two thousand to 10,000 pulsed cycles were used for calibration and other experimental studies. The length of run is operator selectable depending on sensitivity goals. For example, if waste were known to be TRU waste, then one could choose fewer pulses to obtain adequate counting rates. The pulse repetition rate is 50 per second in the Smal1 Package Counter, but other repetition rates are selectable if compensation is made in the early and late gates.

\section{EQUIPMENT}

\subsection{Sma11 Package Counter Chamber}

Counting chamber internal dimensions for normal operation are $600-\mathrm{mm} \times 483-\mathrm{mm} \times 900-\mathrm{mm}$. Two banks of three $\left(762-\mathrm{mm}\right.$ tall) ${ }^{3} \mathrm{He}$ tubes are positioned in the left and right walls to detect the fission neutrons. Figure 1 shows the assay chamber with the detector arrangement. A moderator assembly containing a neutron generator is positioned in the back of the counting chamber. The moderator assembly surrounds the neutron generator and uses a special design incorporating lead to increase neutron flux and graphite as a moderator. This arrangement gives a fairiy uniform neutron emission at the face of the moderator assembly. Over the course of this work, two different generators were used. The original generator was a Sandia Model MA-165 "Zetatron" supplied by Oak Ridge National Laboratory and installed by the system vendor, Pajarito Scientific Corporation, when delivered to the Rocky 
Flats Plant. Upon its failure, a Model A-210 generator supplied by MF Physics was installed. The latter was used since November, 1992.

\subsection{Temporary modification of detector geometry}

The usual 483-mm (19 in.) separation of detectors was temporarily modified for a small series of runs during the period when the MA-165 generator was installed. This modification was tested in order to provide a lower limit of detection and to compare performance to be expected if sample diameters were administratively restricted to $216-\mathrm{mm}(8.5 \mathrm{in}$.) diameters. After experiments in this geometry, the usual separation was employed for most experimental work.

\section{EXPERIMENTAL}

\subsection{Cavity Map Experiment.}

Using a 635 and $300-\mathrm{mg}{ }^{235} \mathrm{U}$ sources in depleted uranium standards, the fissile signal response $\left(F_{s}\right)$ was mapped as a function of horizontal displacement in two perpendicular directions at constant height. The 635-mg source was used with the MA-165 generator and the 300-mg source with the A210. Five heights were used to provide coverage of the available sample volume. In other words, a source was incremented to specific planar locations parallel to the floor. Kept at a constant height, acquisitions were made at each location. A 3-D representation was plotted of $F_{s}$ vs. source location at one vertical height and is shown in Figure 3.

The purpose of this experiment was to identify the area in the counting chamber where the response was flattest and the fissile measurement least variable. A statistical analysis determined a $100-\mathrm{mm}$ diameter area in the center of the counting chamber gave less than $12 \%$ error at a $95 \%$ C.L., for this quantity of material. Performing this measurements at different height locations gave nominal variance, provided the plane was within the active area of the ${ }^{3} \mathrm{He}$ detectors. Since the ${ }^{3} \mathrm{He}$ tubes have an active length of $-610-\mathrm{mm}$, most small packages should not be limited by this.

\subsection{Study of matrix effects.}

These experiments consisted of measurements of the empty chamber and eight materials listed below to simulate the most common waste matrices encountered in past recovery operations at the Rocky Flats Plant. These were:

\footnotetext{
- Newspaper

- Newspaper (Wet)

- Newspaper (High Density)

- Newspaper (High Density/Wet)

- 20 liter Polyethylene pail with peat moss

- 20 liter Polyethylene with PVC

- Boxed steel

- Boxed steel and peat
} 
A depleted uranium source $\left(0.2 \%{ }^{235} \mathrm{U}\right)$ equivalent in fissile signal to 632 mg WG Pu was positioned in several radial and height locations within the matrices. The containers were counted and a net fissile signal $\left(F_{s}\right)$, obtained, (see paragraph 3.3). Average calibration constants were weighted based on the geometric ratio of the volume of the source location to the total volume of the matrix container. The neutron generator was set at 50 pulses/sec and produced $10^{6} 14-\mathrm{MeV}$ neutrons/puTse. These experimental sets were normalized at 4000 interrogating pulses requiring less than 2 minutes per acquisition. All containers for which data are presented were placed on a $100-\mathrm{mm}$ tall stand in the center of the counting chamber so that samples would be in the volume where response was least variable.

\subsection{Other experiments after neutron generator replacement.}

The Zetatron neutron generator that came with the SPC failed to trigger consistently after the measurements in paragraph 3.2 were made. This led to its replacement with a MF Physics neutron generator model\# A-210, purchased for the SPC by Safeguards Measurements. The installation was not without some difficulties. Although the A-210 is the same diameter, its height is 3-inches taller than the Zetatron. This led to a modification of the moderator chamber where the generator rests.

Experiments to determine the background of the new neutron generator were complicated by problems discovered with the detector system. Specifically, the pre-amps were mounted behind the display monitor. The detector system lower discriminator threshold was adjusted slightly above this white noise edge and above the level of smaller fissile signals.

Once the pre-amps were moved, the signal-to-noise ratio improved and the discriminator threshold was lowered. A comparison of the two generator backgrounds ( $\mathrm{bkg}$. ), showed that although the A-210 mean background was now approximately twice as great as the original Zetatron, its variance was half as much. The A-210 therefore has a lower 1 imit of detection $\left(L_{0}\right)$, which is a factor of two better than the original Zetatron with the higher threshold setting. The cavity response map was experimentally indistinguishable from the map made with the original generator.

At this point we performed fissile analysis of two mock-up matrices, 1) dry cellulose and 2) lights miscellaneous metals. The matrix container for both was a $\mathrm{CH}_{2} \mathrm{Clam}$-she $71,178-\mathrm{mm}$ ID, approximately $406-\mathrm{mm}$ in height with an aluminum tube running top to bottom through its vertical center. Two 150-mg ${ }^{235} \mathrm{U}$ CRM-115 New Brunswick Laboratory sources were placed in several different locations in the tube to get an empirical measure of the variability of $F_{s}$ due to source location. Thirty acquisition were made for each location.

\subsection{Calibration calculations.}

The calculation for $F_{s}$ is made as follows:

$F_{s}=$ (Early Gate counts- Late Gate counts)/Flux Monitor counts

The calibration constant $K$ was calculated as shown: 
$\mathrm{K}={ }^{235} \mathrm{U} \mathrm{mg} / \mathrm{F}_{\text {net }}$

where $F_{\text {net }}=\left(F_{3}\right)^{*}-$ Bkg and $\left(F_{3}\right)^{*}$ is the averaged signal from different locations.

The calculation of the calibration constant uncertainty $\sigma_{\mathrm{k}}$ was made as follows:

$\sigma_{\mathrm{x}}=\sqrt{\left(\sigma_{1}\right)^{2}+\left(\sigma_{\mathrm{p}}\right)^{2}+\left(\sigma_{\mathrm{bkg}}\right)^{2}}$

where $\sigma_{1}=$ variance of the individual $F_{s}$ measurements

and $\sigma_{p}=$ the variance of $F_{\text {s }}$ due to position

and $\quad \sigma_{b k g}=$ the variance of the background of the empty matrix

For cellulose, $K$ was calculated to be $9155 \pm 1186$ and $11,558 \pm 3374{ }^{235} \mathrm{U}-\mathrm{mg} /$ $\mathrm{F}_{\text {net }}$ for 7 ight metals at a $95 \%$ confidence interval. Conversion from ${ }^{235} \mathrm{U}$ to ${ }^{239} \mathrm{Pu}$ can be made ${ }^{3}$ by dividing $\mathrm{K}$ by 1.5 , and propagating the $-2 \%$ uncertainty. The plutonium masses are predicted by:

$$
M_{\text {ou }}(\mathrm{mg})=(9155 / 1.5) * F_{\text {net }}
$$

for cellulose, and

$M_{\text {ou }}(m g)=(11,558 / 1.5) * F_{\text {net }}$

for metals.

\section{OBSERVATIONS}

The data listed in Table 1 are the compilations of the fissile signals from ${ }^{235} \mathrm{U}$ in depleted uranium that were converted to mili igrams of WG PU. The measurements of minimum detectable mass were similar to Curries's definition of $L_{0}$ at the $95 \%$ confidence 1 imit. To remain statistically conservative we increased Currie's definition from $3.29 \sigma$ to $4 \sigma$ above the background mean in order to compensate for variability due to sample location within the matrix and for the fact that the fissile signal response of the counting chamber was a saddle-shaped distribution, shown in Figure 3 . The counting statistics that were described by a Poisson distribution would be folded into that saddle-shaped distribution. This total distribution would neither be normal nor a Poisson distribution. Conservative estimates of variability for "typical" assays were $\pm 88 \%$ at $L_{0}$ and $\pm 18 \%$ for $\geq 500 \mathrm{mg} W G$ Pu at confidence level $=0.95$.

Except for PVC, all other matrices in Table 1 are below the $100 \mathrm{nCi} / \mathrm{gram}$ 7 imit set by DOE Order 5820.2A. The reason PVC proved less amenable to DDT is due to the large thermal cross-section of the constituent chlorine. Approximate calculations of the macroscopic cross section of the PVC matrix indicate the interrogating neutron flux was attenuated approximately $50 \%$. This agreed well with our observations, when wet newspaper was compared to 
PVC. Both matrices have approximately the same hydrogen concentrations, but the wet newspaper with its smaller cross section has a factor of 3 greater fissile response. Even so, PVC would be under the $100 \mathrm{nCi} / \mathrm{gram} 1$ imit if its matrix mass were increased a few kilograms.

Figure 4 illustrates how the fissile response is a function of the hydrogen concentration and the macroscopic cress section. The top set of points represents cellulosic combustibles. The fissile signal trends slowly downward as the hydrogen concentration increases. Matrices of dense materials that have moderately high neutron absorption cross sections (steel, PVC) have a dramatically smaller fissile signal by comparison.

We used a smaller $32-\mathrm{mg}$ Pu WG equivalent source when counting in the "close geometry" of Figure 2. The number of interrogating pulses was $10,000$. The $L_{0}$ was improved a factor of 4 . This effectively lowered the minimum detectable mass to $0.5-\mathrm{mg}$ WG Pu, or $6 \mathrm{nCi} / \mathrm{gram}$ in dry cellulosic materia]. With the higher fluxes available from the A-210 generator, even lower values may be obtained in the "close geometry".

\section{DISCUSSION}

The SPC can sort the matrices tested at the $100 \mathrm{nCi} / \mathrm{gram}$ level providing the following are true:

- Accurate calibration constants have been established for matrices to be measured,

- The matrices are reasonable simulations of process samples,

- There are no large lumps of fissile material,

- There is a reasonable mass of matrices and the hydrogen density is not too high, and

- No neutron poisons (boron or cadmium) are present in large quantities.

These conditions should be met for most foreseeable non-conforming items and indeed for most waste. However, personnel from Technical Investigations and Safeguards Measurement groups need to discuss this potential problem and how to provide a decision tree in software to minimize the probability of counting TRU packages with severe $\mathrm{Pu}$-lumping problems.

The large differences in the hydrogen concentration or density of waste matrices will not pose a problem when measuring fissile material in packages of about $230-\mathrm{mm}(9-$ in.) or less diameter. The wet peat in 201 pails was a more severe test than expected for most anticipated waste packages. A decision tree can be put into menu driven software to allow selection of appropriate calibration constants for large diameter wet combustibles, for example.

The DDT technique has an $L_{0}$ an order of magnitude lower than other techniques using the same acquisition time. For example, photon counting in a combustible matrix is far less sensitive per unit time and in dense matrix such as stee], that technique would be at an even greater disadvantage due to the large self-absorption of the photons. 
The minimum detectable mass of the SPC can be further improved a factor of 4 by reducing the counting chamber volume $50 \%$. Although this restricts sample geometries, for thin packages such as a highly compressed 140-liter drum, it could prove to be highly advantageous. It would allow the sorting of smaller packages at the $10 \mathrm{nCi} / \mathrm{gram}$ range, which may be the next specific activity barrier we may have to meet. Also, the counting efficiency could be increased with more detectors.

For packages that are in the TRU waste category, the calibrations need to be extended to higher gram values. We propose to do this with Pu standards when the counter is installed in its operational location. Under current plant rules, we cannot handle the required standards in our laboratory in Building 881 .

\section{ACKNOWLEDGEMENTS}

We gratefully acknowledge the assistance of personnel at Pajarito Scientific Corporation who helped with initial cavity response studies and who provided the temporary detectors for the close geometry measurements. Mr. Frank Burgamo of MF Physics, Inc. aided in replacing the failed MA-165 neutron generator. Mr. Mark Chard of the RFP Standards Laboratory provided the Certified Reference Materials of depleted uranium (CRM-115).

\section{REFERENCES}

1. J. T. Caldwel1, et al., "The Los Alamos Second Generation System for Passive and Active Assays of Drum-Sized Containers," Los Alamos National Laboratory Report LA-10774-MS, Sept. 1982 p 2.

2. "Passive Nondestructive Assay of Nuclear Materials," H.0. MenTove, et a1., Eds., NUREG/CR-5550, LA-UR-90-732, p 592.

3. J. T. Caldwell, ibid., p. 30.

4. L. A. Currie, Analyt. Chem. 40 (1965) 586. 


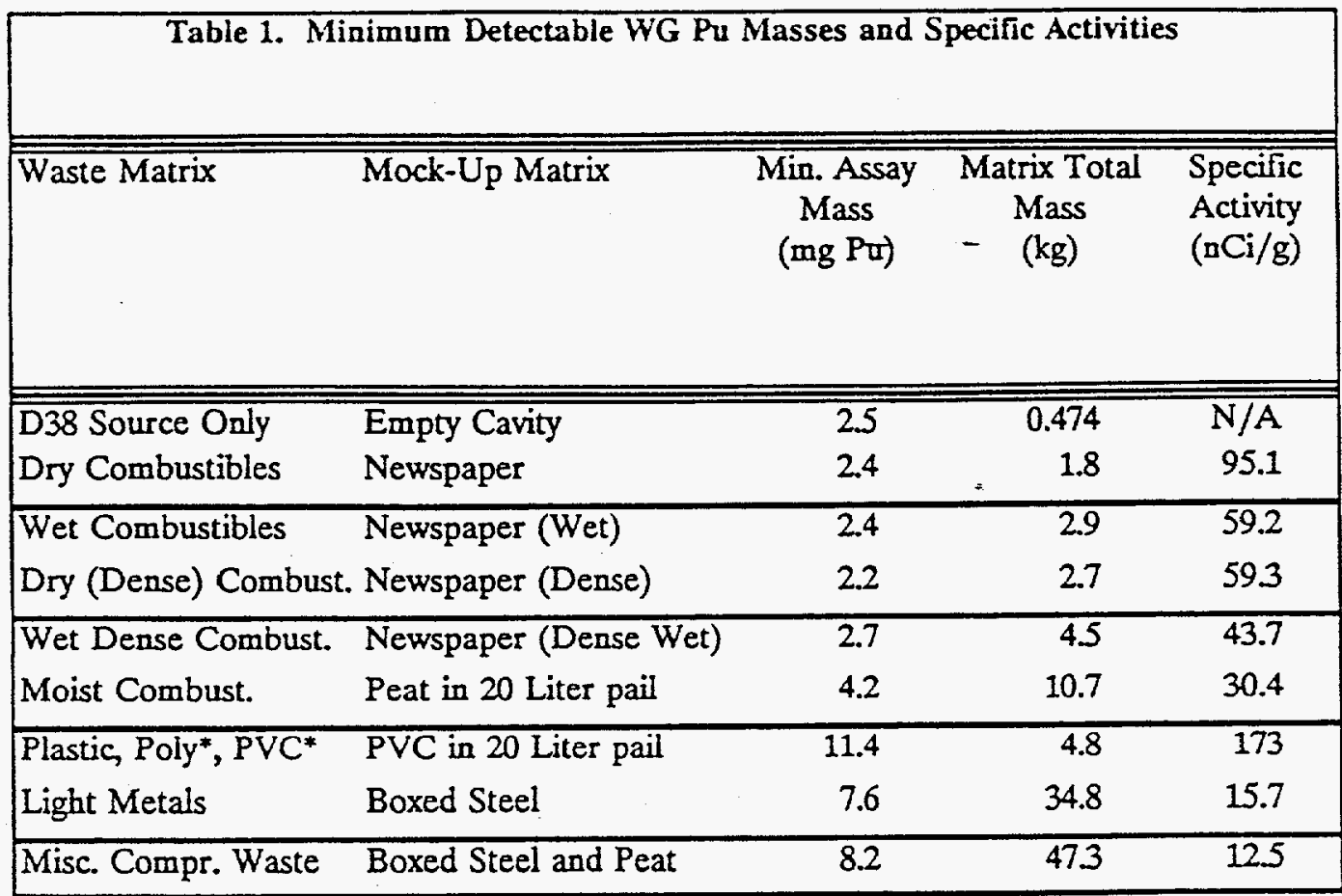

* Poly $=$ Polyethylene, $\mathrm{PVC}=$ Polyvinyl Chloride 


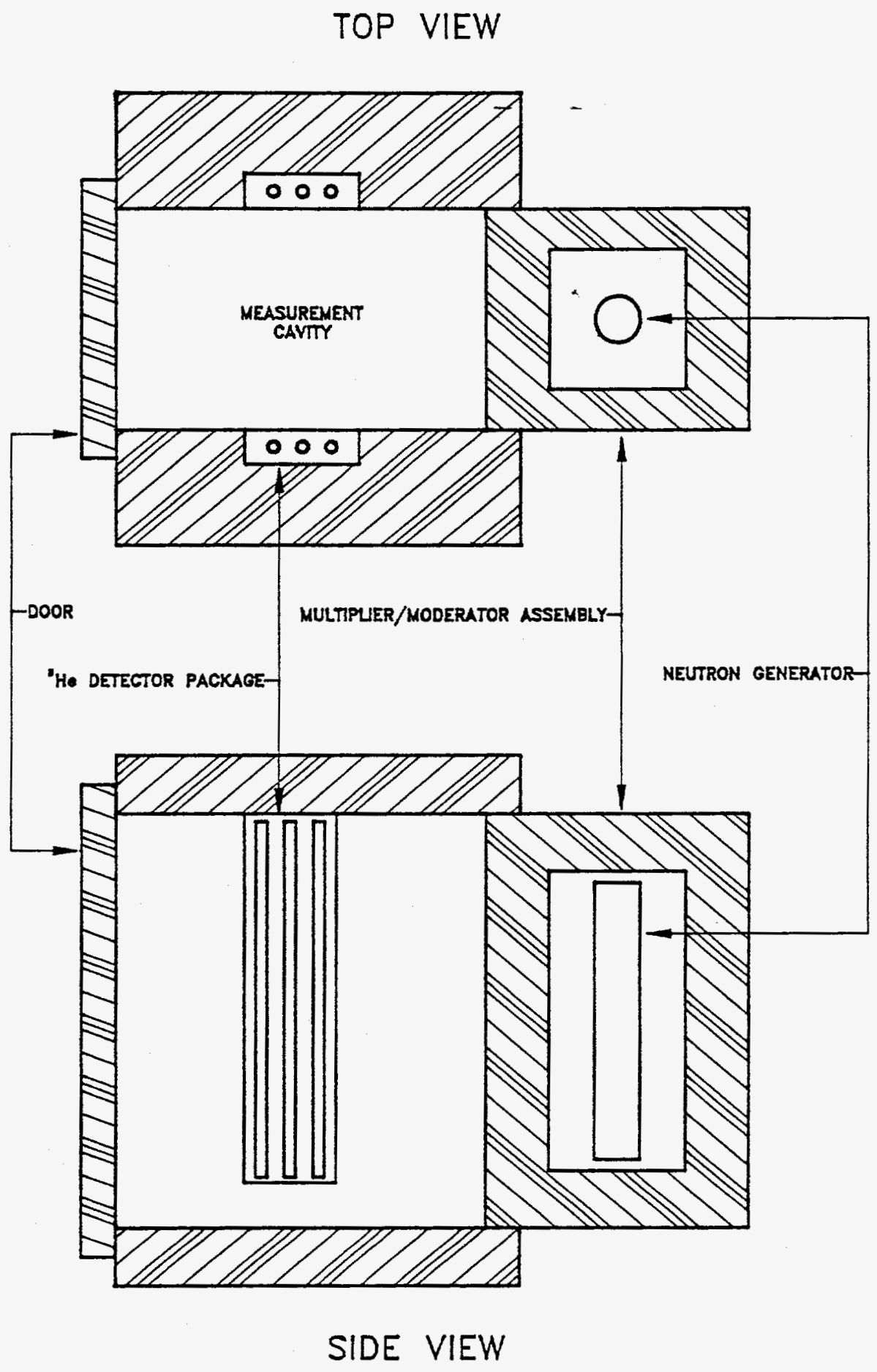

Figure 1. Views of the Active Assay Small Package Counter 


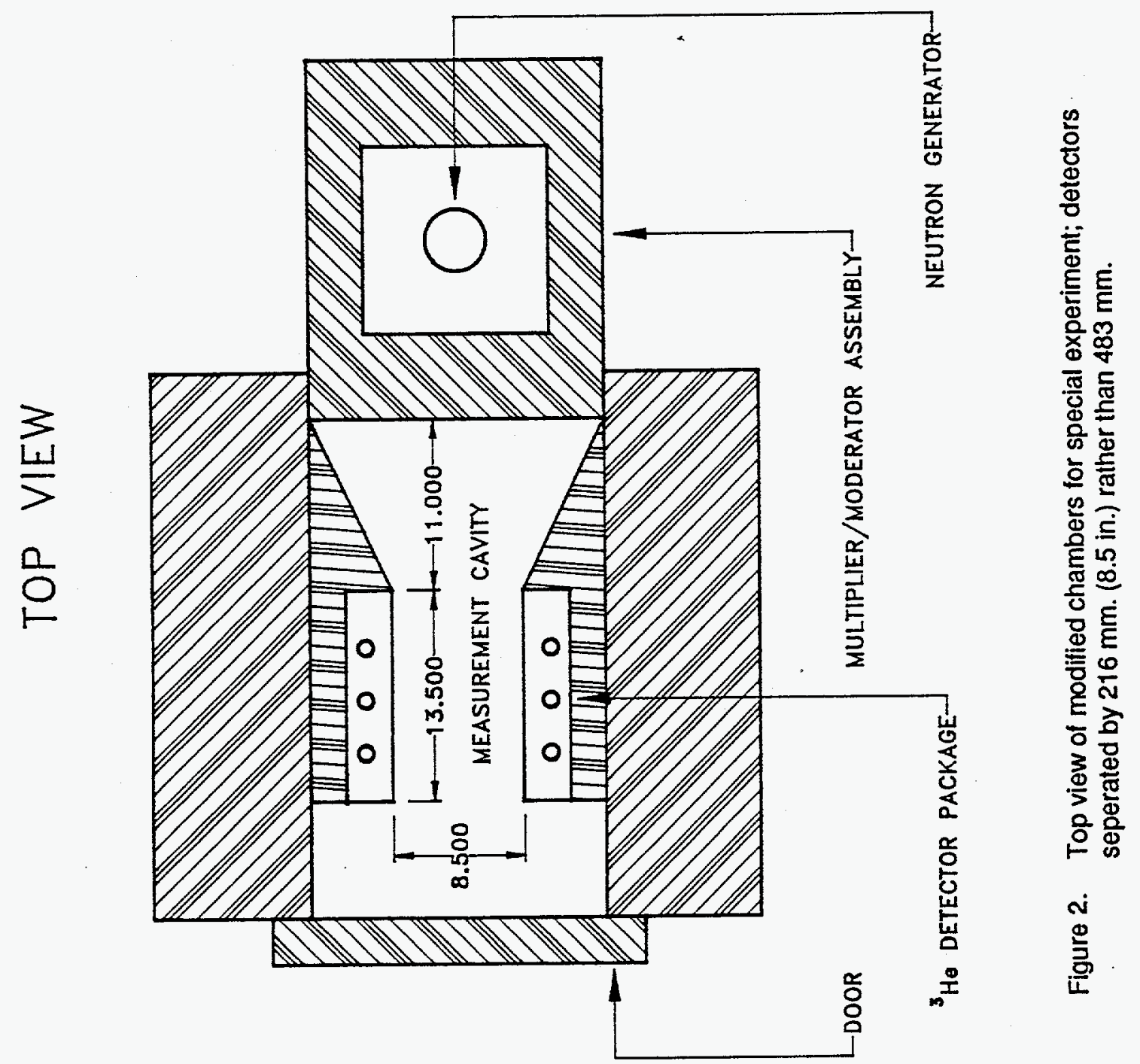




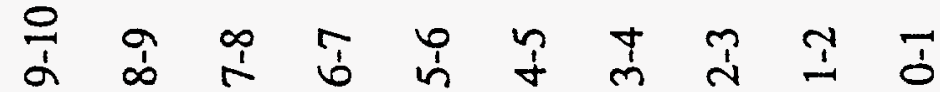 口曰回回圆圆图圆}

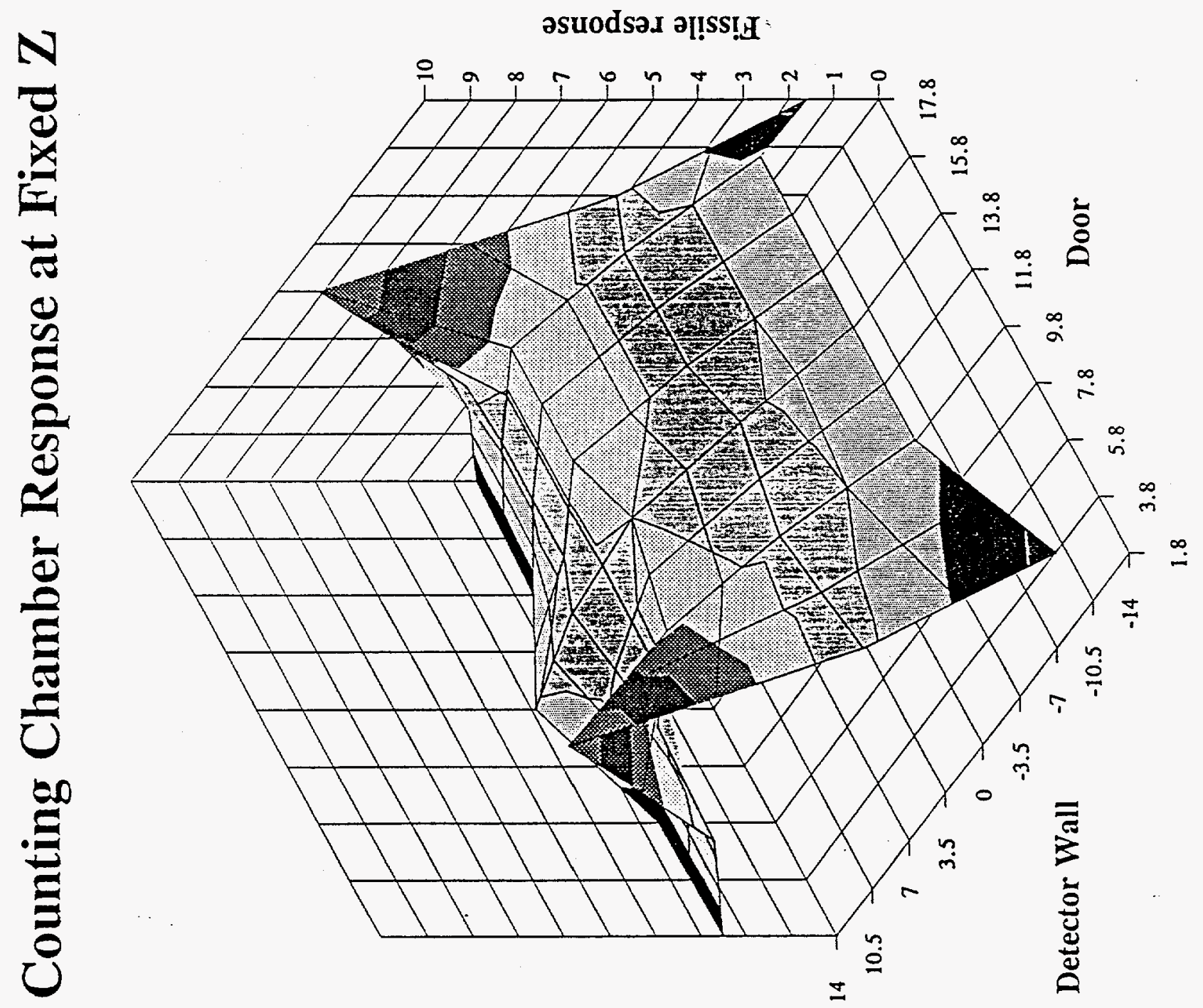




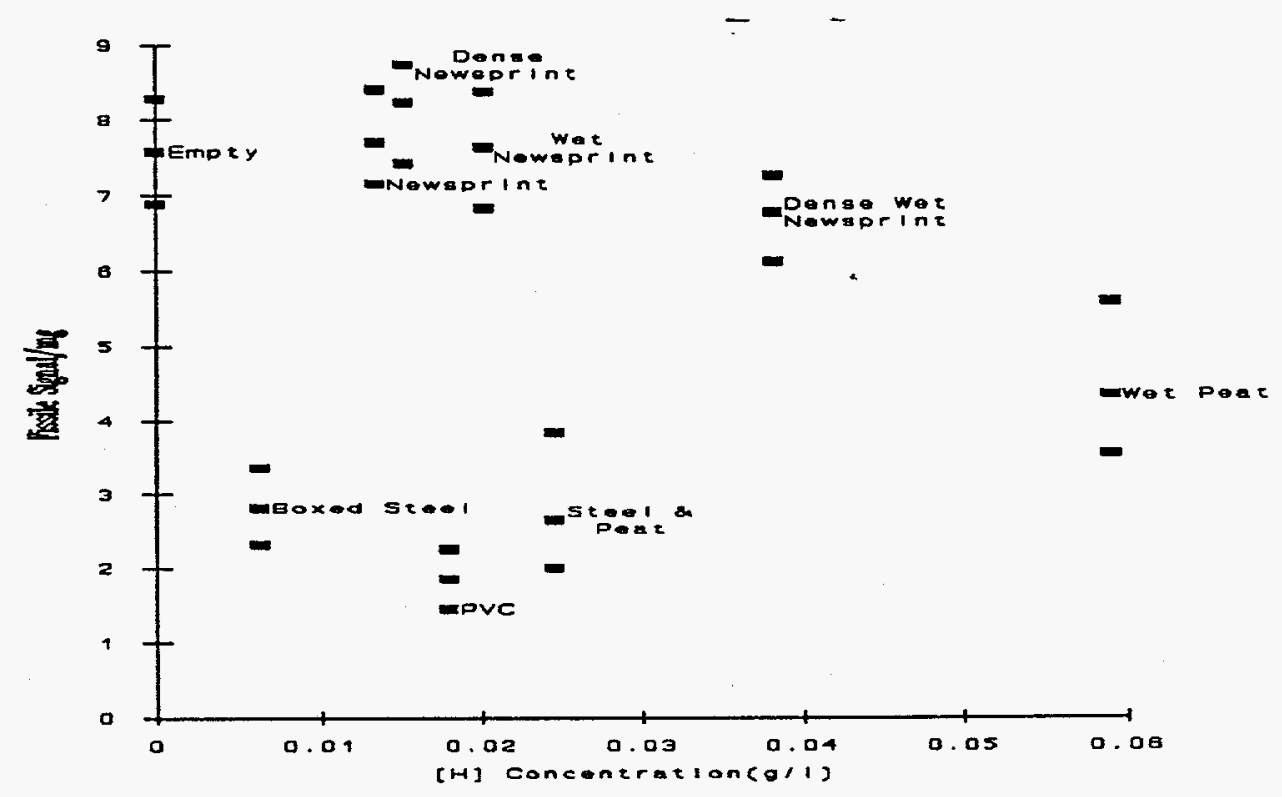

Figure 4. Fissile signal per $\mathrm{mg}$ of Pu vs hydrogen concentration. Note: Each set of 3 vertically aligned data represent from top to bottom, upper end of range of responses, average response of a set of 18 different locations in the counting chamber and lowest end of the range of responses. 